\title{
Modern Italy, 1995-2020: the journal's first quarter-century
}

\author{
Penelope Morris ${ }^{*}$ and Mark Seymour ${ }^{2 *}$ \\ ${ }^{1}$ School of Languages and Cultures, University of Glasgow, UK \\ ${ }^{2}$ History Programme, University of Otago, Dunedin, New Zealand
}

This final number of Modern Italy's twenty-fifth anniversary year is a guest-edited special issue on the theme Italians Beyond Italy/Italy Beyond Italians. It is also the last issue for the journal's general editors of the past six years, Penelope Morris and Mark Seymour. By way of a farewell 'editorial', in this article we cast a look back over the journal's first quarter-century, from its genesis as an evolution of the Association for the Study of Modern Italy's annual newsletter, through various metamorphoses, into the established quarterly publication of the present day.

In the editorial of the journal's inaugural issue in November 1995 (see Fig. 1), John Pollard notes that the hope that ASMI would one day have its own journal went right back to the founding of the Association itself in 1982, and to its first chair, Christopher Seton-Watson. Pollard succeeded Denis Mack Smith as the third Chair of ASMI in 1992, and three years later, he and his editorial team - John Dickie and Simon Parker - launched the journal's first issue, based on the highly successful 1994 annual ASMI conference on 'The Italian Crisis'. The foundation of the journal was also, as Pollard noted, a response to a particular moment in the study of Italy and the history of the nation itself:

The time is now right for Modern Italy. Modern Italian studies are flourishing in the British Isles, and indeed in the English-speaking world, as never before. Non-literary Italian studies have grown as the curriculum of departments of Italian has broadened. Italy has also become of greater significance for European studies, area studies and comparative social and political sciences, while the number of academics working in these fields has increased accordingly. In historical studies, as well, there is an awareness of the continuing relevance of Italy to the history of the Mediterranean as a whole and of Italy as a major source of emigration throughout the 'new world' and as a small but significant colonial power in its own right. Finally, in the last decade there has been greater public interest in Italy due to its recognition as a key partner in the European Union. ${ }^{1}$

While the political crisis of the early 1990s was an obvious focus for a first issue, it was also made clear from the start that the journal was interdisciplinary, and that contributions would be welcome across a broad range of subjects.

*Emails: penelope.morris@glasgow.ac.uk and mark.seymour@otago.ac.nz

(C) The Author(s), 2020. Published by Cambridge University Press on behalf of the Association for the Study of Modern Italy. This is an Open Access article, distributed under the terms of the Creative Commons Attribution licence (http://creativecommons.org/licenses/by/4.0/), which permits unrestricted re-use, distribution, and reproduction in any medium, provided the original work is properly cited. 


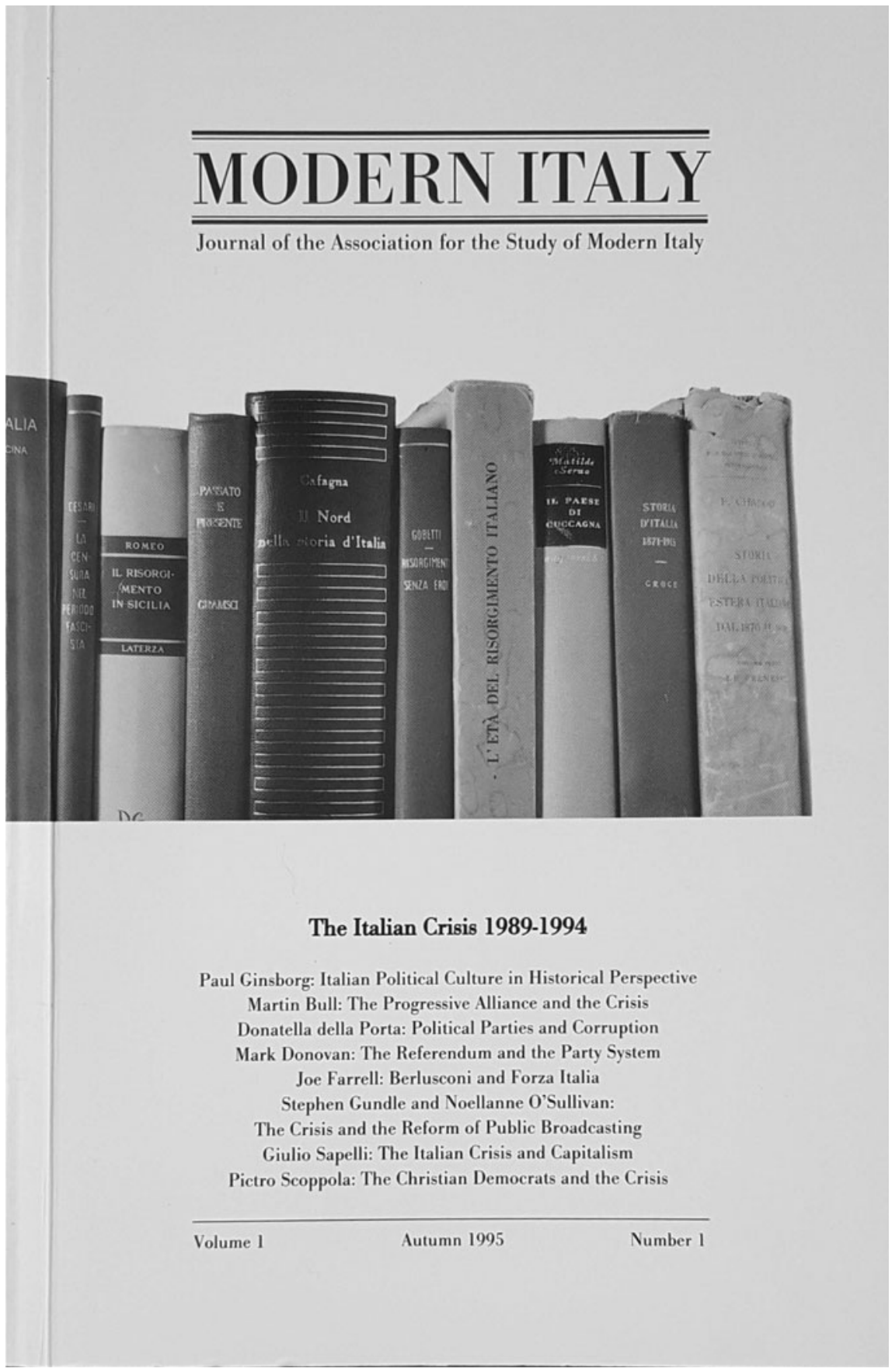

Figure 1. Modern Italy, Vol 1. No. 1, Autumn 1995 
The Association for the Study of Modem Italy (ASMI)

The Association was founded in November 1982 with the following purposes, as defined in its constitution:

(a) To bring together persons in the United Kingdom who are interested in modern Italy, from whatever discipline or profession.

(b) To organize conferences, meetings, seminars, lectures and exhibitions.

(c) To publish newsletters and other material.

(d) To seek co-operation with appropriate institutions and individuals in Italy and the United Kingdom.

The annual subscription rates are $€ 20$ for ordinary and overseas members, $£ 25$ for institutions and $€ 7$ for students and the unwaged.

The officers of the Association are: Chair: John Pollard; Secretary: John Foot; Treasurer: David Laven; Honorary President: Christopher Seton-Watson; Honorary Vice-President: Denis Mack Smith.

ASMI is registered under the Charities Act 1960: Charity Number: 296240.

Membership of ASMI includes a subscription to Modern Italy, together with the bi-annual newsletter ASMI News. Members are also entitled to reductions on fees for conferences and seminars organized or sponsored by ASMI.

Please address membership applications to:

The ASMI Treasurer, Dr David Laven, Department of History, The University of Reading, Whiteknights, Reading, RG6 2AA, United Kingdom.

\subsection{7) Ham MODERN ITALY}

General Editor

John Pollard (Anglia Polytechnic University, Cambridge)

\section{Associate Editor}

Simon Parker (University of York)

\section{Reviews Editors}

John Dickie (University College, London)

Lucy Riall (Birkbeck College, London)

\section{Editorial Committee}

Anna Bull (University of Bath)

John Foot (University College, London)

Stephen Gundle (Royal Holloway,

London)

David Laven (University of Reading) Jonathan Morris (University College,

London)

Perry Willson (University of Edinburgh)

Editorial Advisory Committee

Walter Adamson (Emory University,

Atlanta)

Percy Allum (University of Reading)

Richard Bellamy (University of Reading)

Richard Bosworth (University of Western Australia)

John A. Davis (University of Connecticut)

Donatella della Porta (University of

Florence)

David Ellwood (University of Bologna)

David Forgacs (Gonville \& Caius College,

Cambridge)

Russell King (University of Sussex)

McGregor Knox (London School of

Economics and Political Science)

Denis Mack Smith (Oxford)

Marco Meriggi (University of Verona)

John MacDonald (King's College, London)

Uffe Ostergaard (Aarhus University)

Luisa Passerini (University of Turin)

Paolo Pezzino (University of Pisa)

Giulio Sapelli (Istituto Feltrinelli, Milan)

Pietro Scoppola (University of Rome, La Sapienza)

Christopher Seton-Watson (Oxford)

Frank Snowden (Yale University)

Penny Sparke (Royal College of Art,

( London)

Figure 2. Inside cover, Modern Italy, Vol. 1 No. 2, Autumn 1996

Between 1995 and 1997, the journal was published annually. The inside cover of the second issue (1996) listed a full editorial team of editor (Pollard), associate editor (Simon Parker), reviews editors (John Dickie and Lucy Riall), an editorial committee (Anna Bull, John Foot, David Laven, 


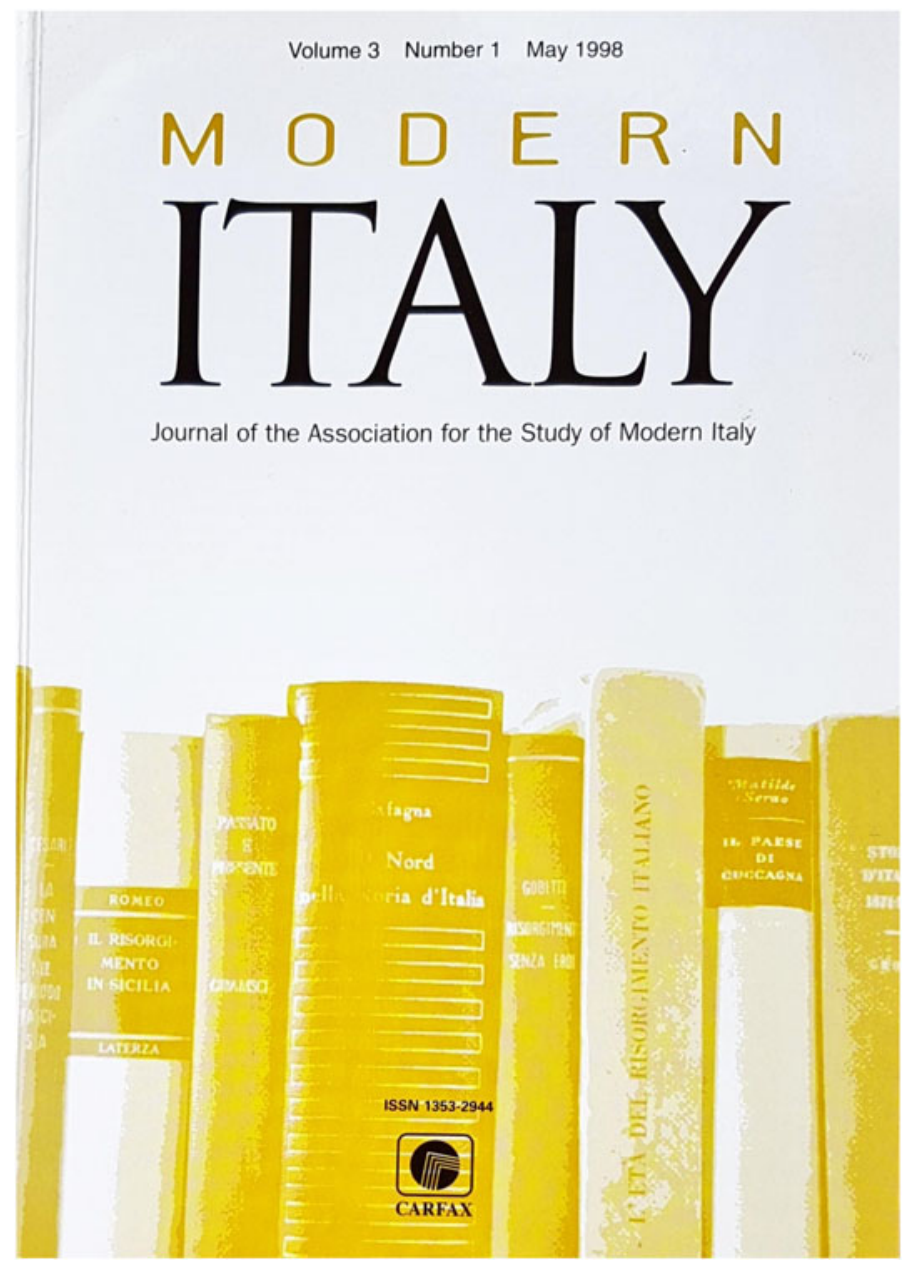

Figure 3. Cover, Modern Italy, Vol. 3 No. 1, May 1998

Jonathan Morris, and Perry Willson), and an international editorial advisory committee of 21 scholars (see Fig. 2). This issue also introduced a 'Contexts and Debates' section, as a development of the kind of essays that appeared in the annual ASMI Newsletter that was the journal's predecessor.

In 1998, the journal expanded to two issues per year, the second of which was on the the 'Charisma and the Culture of Personality in Modern Italy'. It was guest-edited by Stephen Gundle and Lucy Riall. This began a tradition of approximately half the journal's annual content consisting of themed, guest-edited issues that has continued to the present. Also in 1998, the journal ceased to be an in-house publication and moved to Carfax of Abingdon, which was then the largest publisher of social science and humanities journals in the United Kingdom (see Fig. 3). The journal's editors assured readers that under these new arrangements ASMI would retain ownership and editorial control of Modern Italy and that it would continue to be the 'Journal of the Association for the Study of Modem Italy'. 'The link with ASMI', they commented, 'is undoubtedly Modern Italy's greatest strength, and the contents of the journal will continue to reflect the 


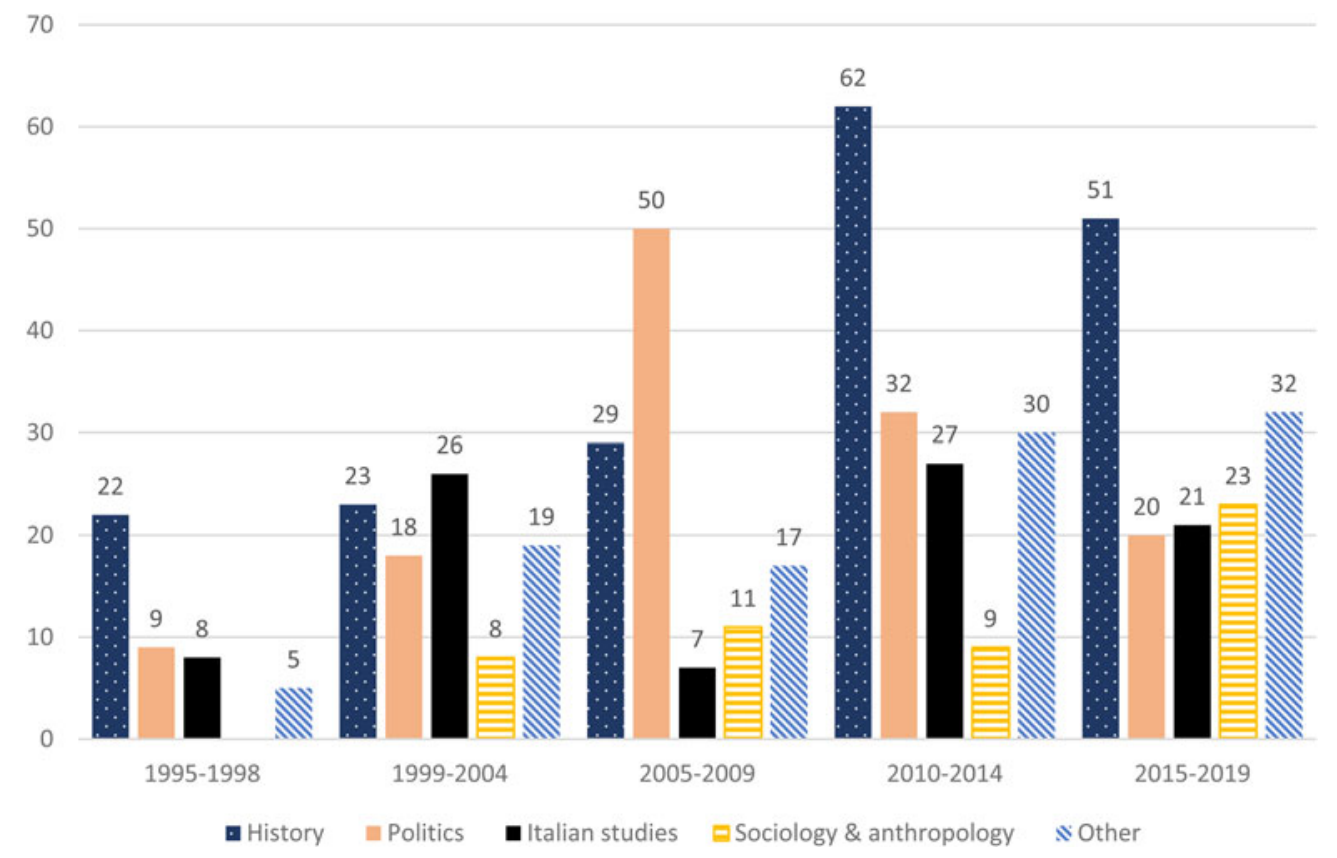

Figure 4. Modern Italy Contributors (Affiliation)

* It should be noted that this graph only gives a broad indication of the discipline of scholars, given the heterogeneous nature of Italian Studies departments.

interests and concerns of the membership.' At the same time, the editors would 'welcome all articles submitted for consideration, regardless of whether they are by members of ASMI or not'. ${ }^{2}$ 1998 was also a year of mergers and acquisitions within academic publishing. Modern Italy's recently adopted publisher, Carfax, was acquired by the Taylor \& Francis Group, and the journal appeared as a Carfax Taylor \& Francis publication from 1999.

By 1999, when John Dickie took over as editor, Modern Italy was well on the road to establishing itself as a leading interdisciplinary journal. In addition to historians and political scientists, the more significant presence of sociologists, anthropologists, scholars in media studies, Italian language and culture more broadly (see Fig. 4) was promoted by special issues, notably 'The Italian Experience of Immigration' (Vol. 4 no. 2, November 1999) and 'Italy in the Digital Era' (Vol. 6, no. 2, November 2001). John Dickie was assisted by associate editor Simon Parker for a year, and was then joined by Mark Donovan as co-editor in 2000. John Dickie and Mark Donovan then continued as co-editors for the next four years until 2004, with the exception of issue 8.1 (2003), in which Donovan was sole editor (with associate editors Martin Brown and Charles Burdett).

In 2005, Martin Bull and Anna Cento Bull became the journal's editors. The fact that the co-editors had the same surname led some to assume that the editorship had become a family affair, but this was in fact a coincidence as the Bulls were not related. Their inaugural issue was also the first to appear under the Routledge imprint of Taylor \& Francis. The new editors' aims were 'to increase the number of submissions and subscriptions to the journal and, at an appropriate point, to expand the journal to three issues per year'. Special issues, which had previously tended to be linked to ASMI conferences, were augmented by scholarship from events sponsored by 


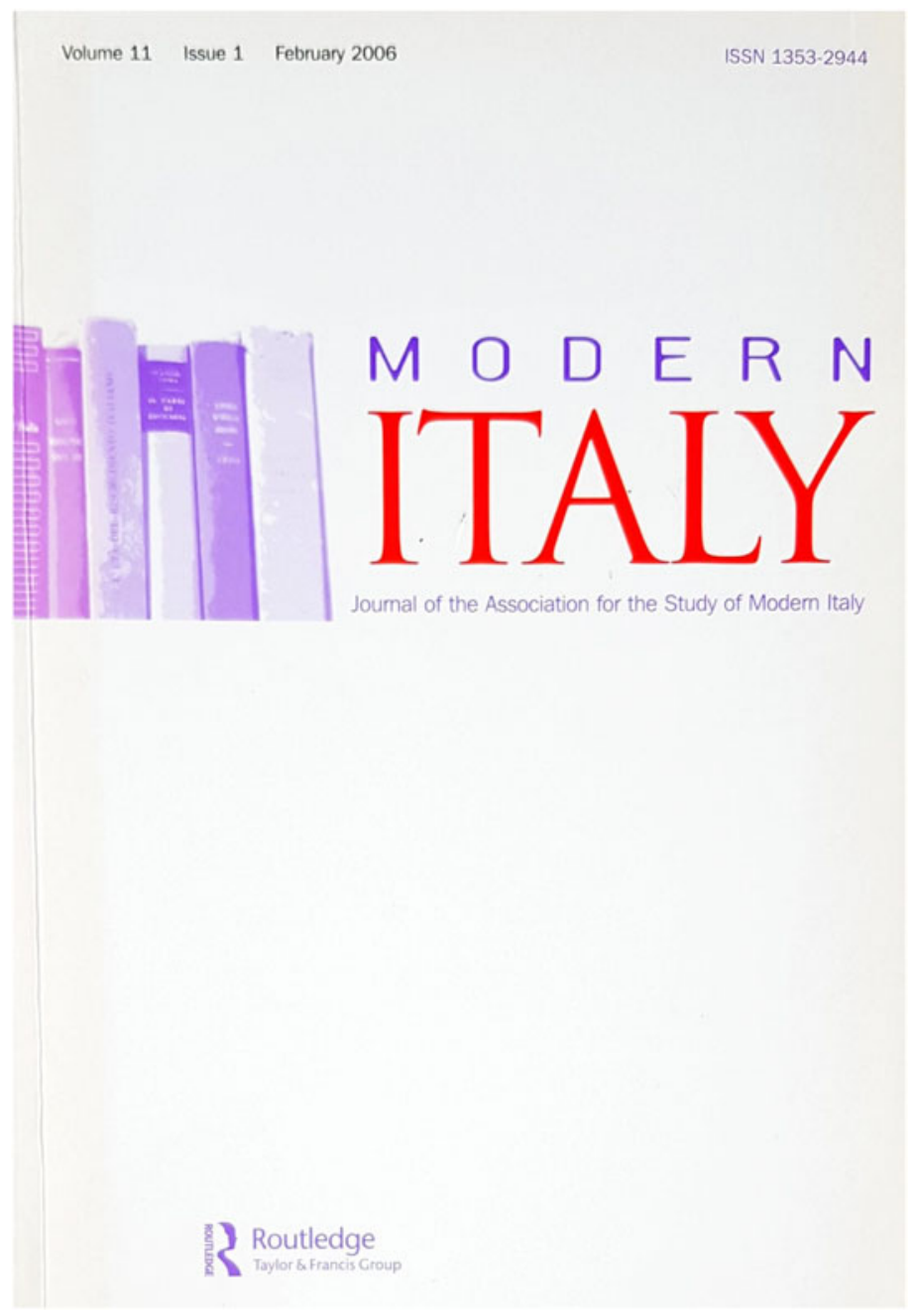

Figure 5. Modern Italy, Vol. 11 No. 1, February 2006

institutions close to ASMI. For example, Vol. 10 no. 1 on 'The Berlusconi Years' (May 2005) was inspired by a series of panels heard at the 2003 Political Studies Association conference in Leicester, UK, while Vol. 11 no. 1 (February 2006), on 'Italian diasporas', drew from scholarship that had been presented at the Institute of Advanced Studies of the University of Western Australia in July 2003. As well as signalling the journal's increasingly global scope, that February 2006 issue also represented the achievement of the new editors' aim to expand the journal: it was the first of three issues per year. To mark the expansion, the journal received a new cover design featuring lilac and red lettering (see Fig. 5), and it also adopted the Harvard in-text referencing system.

Modern Italy flourished under the editorship of Martin Bull and Anna Cento Bull, retaining its multidisciplinary focus and commitment to publishing articles of high quality from a wide range of scholars. A high proportion of contributions from political scientists was a notable feature of this period, although historians, anthropologists, sociologists, and others retained a solid presence 


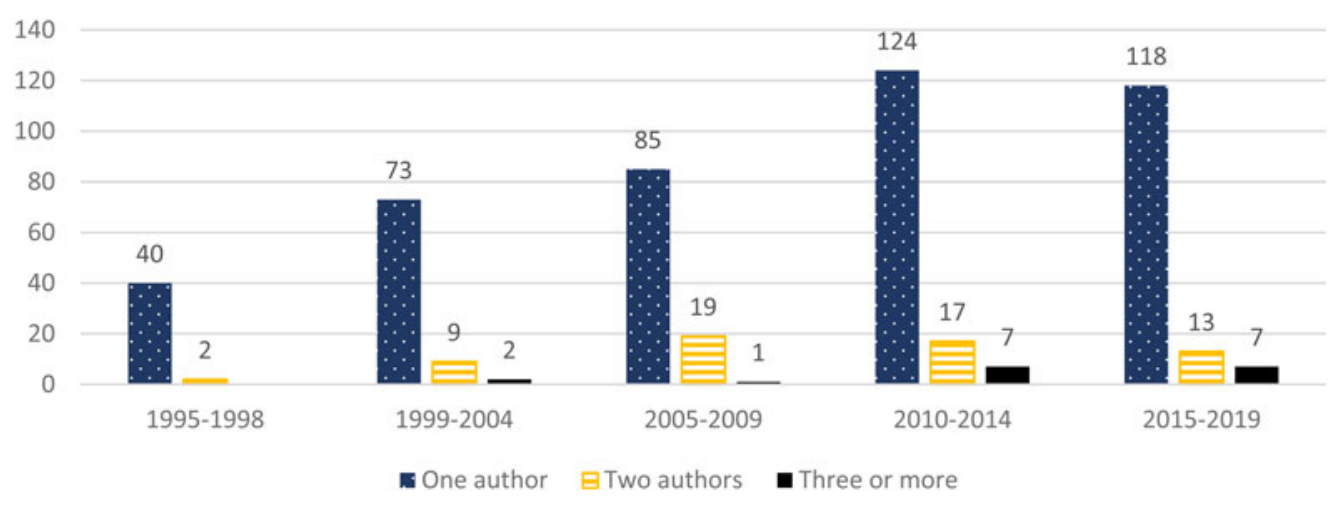

Figure 6. Modern Italy Authorship (single or multiple authors)

throughout the Bulls' editorial term (see Fig. 4). An interesting development was that dual-authored articles doubled in number in this period, possibly a result of the increase in the number of articles written by political scientists. Nevertheless, sole-authored research remained the dominant format (see Fig. 6).

From Vol. 13 no. 1 (2008), only two years after the journal's transition to three issues per year, growth in contributions warranted a further expansion, to quarterly publication — reflecting sustained scholarly interest in Italian studies across the United Kingdom and wider anglophone world. This is something that ASMI's founder, Christopher Seton-Watson, would certainly have been proud of. Alas he died in 2007. In memoriam, ASMI and the journal established the Christopher Seton-Watson Prize, which provided for a sum of $€ 500$ to be awarded annually to the best research article published in Modern Italy. The inaugural Christopher Seton-Watson Prize was awarded in 2009 for an article published in 2008. Occasionally the annually constituted judging committee has split the prize between two articles.

The journal's expansion was at least to some extent due to greater interest on the part of Italian scholars in publishing their work in English. This probably reflects the increasingly international nature of academia in general but could also be linked to the Italian government's first research assessment exercise, the Valutazione Triennale della Ricerca (VTR), introduced in 2004, but covering the period 2001-2003. Fig. 7, while attesting to the continued investment of UK-based Italianists, reveals significant growth in contributions from scholars based in Italian institutions, as well as rising contributions from scholars based in North America and Australasia. Overall, between 2004 and 2009, article submissions to the journal tripled in volume, and the production of special issues no longer derived solely from symposia and conferences. The demand was such that special issues were often fully booked up to two years in advance. The journal's book reviews section had also expanded to the point of requiring the appointment of a dedicated reviews editor, initially Philip Edwards.

In 2010 the editorship of Modern Italy passed to Philip Cooke and John Foot. Nick Carter replaced Philip Edwards as book reviews editor the following year (and was to hold the role singlehandedly until the end of 2015). As Cooke and Foot note in their first editorial, they were taking over at a critical time for Italian Studies in the UK, with Italian Departments under more pressure than ever to cut costs, and many facing the threat of closure or merger. But it was also a moment which offered opportunities. As they put it, 


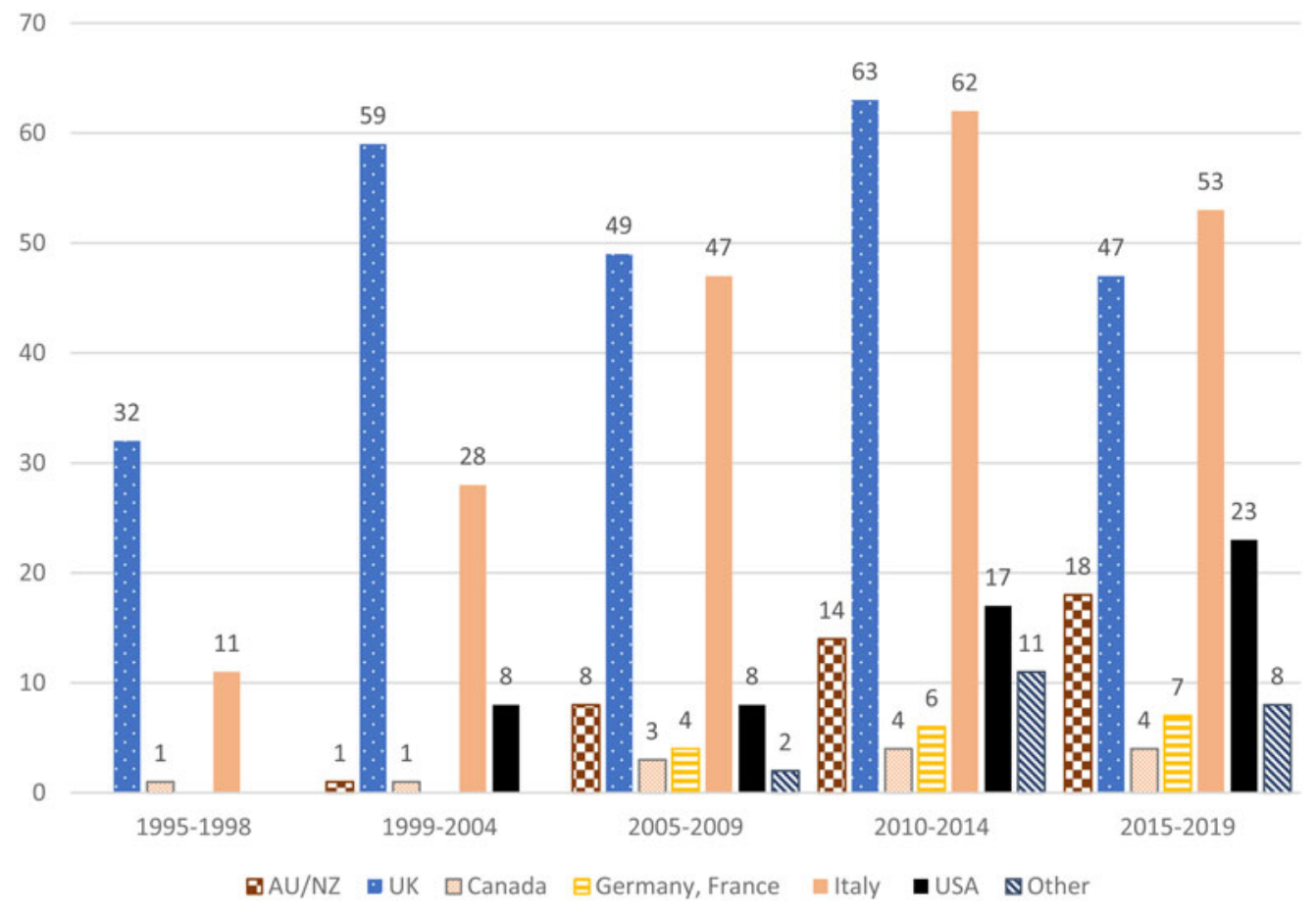

Figure 7. Modern Italy Contributors (Institution location)

In this moment of change we, as editors, would like to expand the range of the journal and to open up its pages to more cross-disciplinary and multi-disciplinary work. We will also seek to build more bridges with ongoing research in Italy and to encourage publication of new and exciting research in a whole series of areas.

Over the next five years the journal extended its geographic and disciplinary reach across institutions in the United Kingdom, Germany, France, and further still, with contributors emerging from Sweden, Canada, Portugal, Mexico, New Zealand, Australia, and North America (see Fig. 7).

Perhaps predictably given that both Cooke and Foot are historians, under their editorship there was a shift in the journal's dominant discipline from political science back to history. On the other hand, the journal's established range of disciplines was increasingly augmented by contributions from scholars of gender studies, disability studies, the life sciences, and migration studies, all of whom engaged with an array of topics and cross-disciplinary perspectives (see Fig. 4), though, possibly the most notable shift under Cooke and Foot's editorship was a further increase in the proportion of articles published by scholars based at institutions in Italy (Fig. 7).

Cooke and Foot also oversaw a major technological transition for the journal, with the adoption of the ScholarOne manuscript system. This system of electronic submission and peer-review management, although complicated to the uninitiated, ultimately greatly facilitates the day-to-day running of the journal, creating a rich archive as it does so. The first research article to be submitted via ScholarOne arrived in June 2010. Because of the long tail of articles submitted and sent out to referees prior to the introduction of ScholarOne (not to mention author and referee resistance to the new system), the editors managed two systems at once for some time. From Volume 16 (2011), the 
$\begin{array}{lll}\text { Volume } 16 & \text { Issue } 1 \text { February } 2011 & \text { ISSN 1353-2944 }\end{array}$

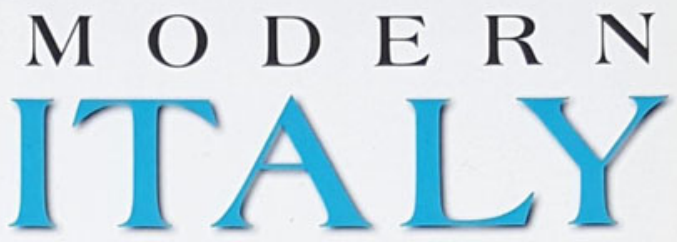

Journal of the Association for the Study of Modern Italy

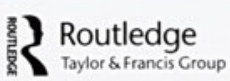

Figure 8. Modern Italy, Vol 16 No 1, February 2011

journal sported a revised and significantly more modern-looking cover (see Fig. 8). The solidly bound Italian tomes that had been a motif on Modern Italy's cover since its inception fifteen years earlier, gave way to a plain white front, with the ITALY of the journal's title in a distinctive blue somewhere between duck-egg and Oxford, and the back cover in the same blue.

From Volume 17 (2012) onwards, the editors appointed two associate editors (Andrea Hajek and Samantha Owen) to help them with the workflow. Towards the end of Cooke and Foot's tenure, deeper changes were mooted at the journal, culminating in the transition to Cambridge University Press as publisher. The change was preceded by negotiations in 2014 between ASMI and three possible publishers. The process was led by ASMI's chair, Stephen Gundle, with the incumbent and incoming editors also extensively involved. The choice of Cambridge 
quietly initiated a new phase for ASMI and the journal, one that has been marked by significantly increased income, allowing both the Association and the journal to expand their activities.

2015 was a year of double transition for the journal: new editors Penelope Morris and Mark Seymour began their term with the challenge of keeping the journal running normally while overseeing the shift of the production process from Taylor \& Francis to Cambridge University Press. Cambridge formally took over from 2016, and the first issue bearing the Cambridge imprint was Vol. 21 No. 1. Alterations to the cover design were minimal: the spine changed from blue to white, and the Cambridge University Press logo featured on the front and back (see Fig. 9). We had inherited a well organised journal with good refereeing procedures, and once the transition process was completed, we aimed to build upon the journal's strengths of interdisciplinarity and worldwide reputation among Italianists.

With one of us based in New Zealand, and the scholarly community increasingly interconnected, we put emphasis on internationalising the journal's editorial team. One of the new initiatives was to diversify the book review editor role with the appointment, from 2016, of an evolving team of three to five review editors, representing the UK and Europe, North America, and Australasia. Andrea Hajek continued as associate editor, sharing her wisdom as managing editor of another journal, and we appointed Giacomo Lichtner, located in New Zealand, as our second associate editor, so that Seymour could call upon expertise and support in the same time zone. The expansion in the number of editorial roles not only meant a more even sharing of the journal's workload, but gave us more scope to aim for gender and seniority balance, as well as notably increased geographical representation. A significant development in the journal's history witnessed over the 2015-2019 period pertains to the gender of Modern Italy's contributors, with female authors, whose numbers had been increasing steadily, eclipsing their male counterparts for the first time (see Fig. 10).

Because Asia has not generally been a natural stronghold of Italian studies, one of our most ambitious internationalisation projects involved running a conference at Mahidol University, Thailand, on the theme 'Italy and Asia', in 2018. This bore fruit as a special issue based on Italy's relationship with Asia (and vice versa), and formed part of an overall strategy to attract more research that viewed Italy comparatively and transnationally. In a similar vein, we have made conscious efforts to raise the profile of the journal elsewhere outside the UK, for example by sponsoring panels at two American Historical Association annual conferences, by forming ties with the US Society for Italian Historical Studies (SIHS) and the Australasian Council for Italian Studies (ACIS), and by organising special-issue launch events at universities in Italy.

Despite the challenges faced by an interdisciplinary journal in indexing and classification systems designed above all for single disciplines, Modern Italy was selected for inclusion in the Thomson and Reuters Emerging Sources Citation Index in 2016, and both the Arts and Humanities Citation Index and the Social Sciences Citation Index in 2019. This also meant that the journal received an impact factor for the first time. It is also graded 'A' across most relevant ANVUR classifications in the Italian system. One of the most fundamental changes of recent years for all journals in the United Kingdom has been the response to demands for Open Access. Modern Italy remains compliant with funder and Green Open Access mandates, allowing deposit of accepted manuscripts in institutional repositories. The journal is classified as 'hybrid', and publishes Gold Open Access articles in return for payment of an Article Processing charge, or under a negotiated Read and Publish deal.

While the role of the editors continues to be a substantial one, the journal is also very much a team effort of course, and absolutely fundamental over the last 25 years have been the journal's 


\section{$\mathrm{MO} \mathrm{D} \mathrm{E} \mathrm{R} \mathrm{N}$

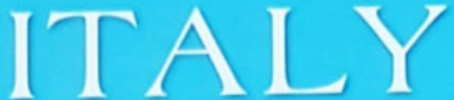

Volume 21 Issue 1 February 2016

EDITORIAL

Penelope Morris and Mark Seymour

OBITUARY

Christopher Duggan 1957-2015

Stephen Gundle

ARTICLES

Matteo Renzi: a new leadership style for the Italian Democratic Party and Italian politics

Eugenio Salvati

Connected and disconnected memoryscapes of the Antigorio Valley: a village under water and a Second World War massacre on a cableway

Hildegard Diemberger

Ransom kidnapping: the anonymous underworld of the Italian Republic

Alessandra Montalbano

Cold-War Trieste: metamorphosing ideas of Italian nationhood, 1945-1975

Fabio Capano

A law made by Italian mothers for Italian mothers? Women politicians and the 1950 law on maternity rights

Pamela Schievenin

'Undesirable Italians': prolegomena for a history of the Calabrian 'Ndrangheta in Australia

Stephen Bennetts

BOOK REVIEWS

\section{Cambridge Journals Online}

For futher information about this journal please go to the journal web site at: journals.cambridge.org/mit

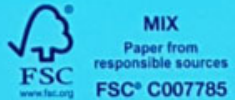

\section{CAMBRIDGE} UNIVERSITY PRESS 


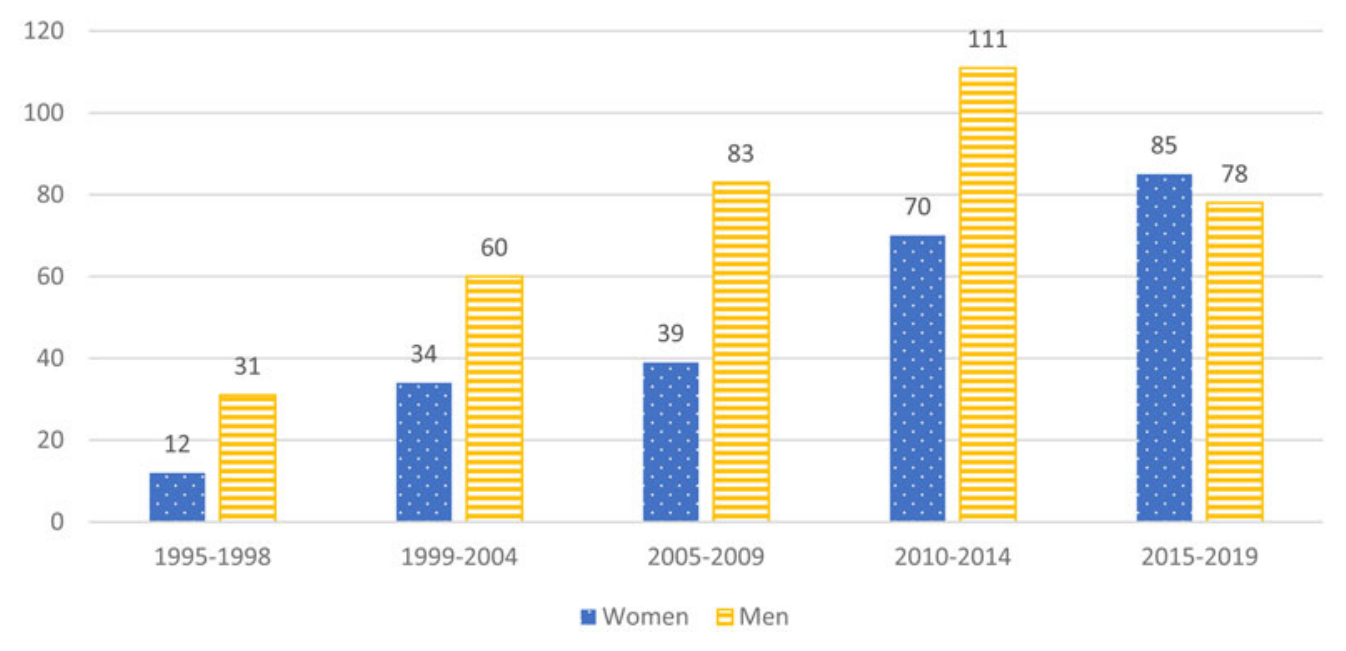

Figure 10. Modern Italy Contributors (Gender)

huge number of anonymous reviewers, from a wide range of disciplines, from across the world. In an increasingly pressured academic environment, their generosity and willingness to provide detailed comments, to re-read and offer further views on revised papers, has been crucial for bolstering the quality of published articles, and underpins the journal's reputation and success. Also vital to this process is the solid core of reviewers and expertise provided by the members of our editorial boards.

Specific and heartfelt thanks for their contributions during our term as editors go to associate editors Andrea Hajek and Giacomo Lichtner, and our book review editors (in chronological order) Nick Carter, Fabio Camilletti, Rebecca Clifford, Piero Garofalo, Francesco Ricatti, Kate Ferris, Roberta Colbertaldo, Milena Sabato, Giovanna Summerfield, Nicolas Virtue and Joseph Viscomi, as well as our hard-working administrative assistants, Emily Ryder and Alessia Zinnari. We also express our thanks to successive chairs of ASMI (Christopher Duggan, Stephen Gundle, Lucy Riall and Philip Cooke) for their constant support, to Stuart Oglethorpe and Ian Mansbridge for their meticulous translation work, to Hilary Horrocks for her everthorough copy-editing, to publisher Taylor \& Francis and then the fabulous team at Cambridge University Press, including Senior Commissioning Editors Martine Walsh then Jamie McIntyre, Production Editors/Content Managers Peter Moorby, Caela Moffat and Rachael Lowther, and ScholarOne support team Richard Horley and Wendy Moore. We are also grateful for the logistical support at various stages in the journal's life from University College London, the University of Salford, and the University of Glasgow.

At the beginning of 2020 , we had looked forward to a particularly celebratory $25^{\text {th }}$ anniversary year for Modern Italy, culminating in some sort of festa at the time of the annual ASMI conference. Alas, by March the development of a global pandemic caused by the COVID-19 virus had cast a shadow over those hopes, and not long after that it became clear that 2020 would go into the history books as one of misfortune on a global scale. Nevertheless, we are confident that the festa is postponed rather than cancelled, and we look forward to in-person celebrations of Modern Italy's first quarter-century when and wherever possible. It has been a fascinating and stimulating privilege to 
edit the journal for the last six years, and we wish our successors, Francesca Billiani and Andrea Mammone, the very best as they launch the journal's next quarter-century.

\section{Acknowledgements}

We would like to thank Dr Violeta Gilabert of the University of Otago for her detailed research assistance on the history of Modern Italy, and for preparing the graphs. We would also like to thank former editors John Dickie, Martin Bull and Philip Cooke for peer-reviewing this article.

\section{Notes}

1. John Pollard, Editorial, Modern Italy 1:1, 1995, p. 1.

2. John Pollard, Simon Parker and John Dickie (Editors), Editorial, Modern Italy, 2:1/2, 1997, p. 2. 